\section{Proctocolitis induced by salicylate and associated with asthma and recurrent nasal polyps}

Sensitivity to aspirin may lead to asthma, rhinitis, urticaria, and angiooedema. ${ }^{1}$ We report on a patient with proctocolitis whose gastrointestinal symptoms went into complete remission with a diet free of salicylates and known cross reacting substances but recurred on double blind oral provocation with aspirin.

\section{Case report}

A 55 year old man was investigated in September 1982. He had a 10 year history of asthma, a five year history of perennial rhinitis and conjunctivitis, and a three year history of chronic urticaria. Histological examination of nasal polypectomy specimens obtained in 1980, 1981, and 1982 had shown a predominant eosinophil infiltrate. He had had diarrhoea with blood and mucus and episodes of pain in the left iliac fossa for three years. In 1980 sigmoidoscopy had shown ulcerative proctitis, and a rectal biopsy specimen had been considered to be consistent with the diagnosis of ulcerative colitis. He had been treated intermittently with sulphasalazine without benefit.

When seen in 1982 he was passing more than 10 , often bloodstained, motions a day (four to six each night) and was often incontinent of faeces. Sigmoidoscopy showed moderately severe proctocolitis extending for $20 \mathrm{~cm}$ with spontaneous bleeding but no gross ulcers. Haemoglobin concentration was $15.9 \mathrm{~g} / \mathrm{dl}$ with normal variables; erythrocyte sedimentation rate was $27 \mathrm{~mm}$ in first hour; and the biochemical profile and urinary 5-hydroxyindole acetic acid concentrations were normal. There was pronounced peripheral eosinophilia $\left(0 \cdot 32-1 \cdot 4 \times 10^{9} / 1\right)$. Ova, cysts, and parasites were not found in the stools. Skin reactions to common inhalant and food antigens were negative. Review of rectal biopsy specimens from 1980 and 1982 showed active non-specific inflammatory changes. The first biopsy specimen showed surface mucosal ulceration and crypt abscesses, which contained many eosinophils. Eosinophils were prominent in the lamina propria in both biopsy specimens. Paneth's cells were not seen, and there was no evidence of protozoal infection.

He was subjected to open, followed by double blind, provocation tests: these showed that his bowel, respiratory, nasal, eye, and skin symptoms could all be induced by administration of salicylate but not sulphapyridine. The figure shows his response to provocation with $50 \mathrm{mg}$ aspirin. Within two weeks

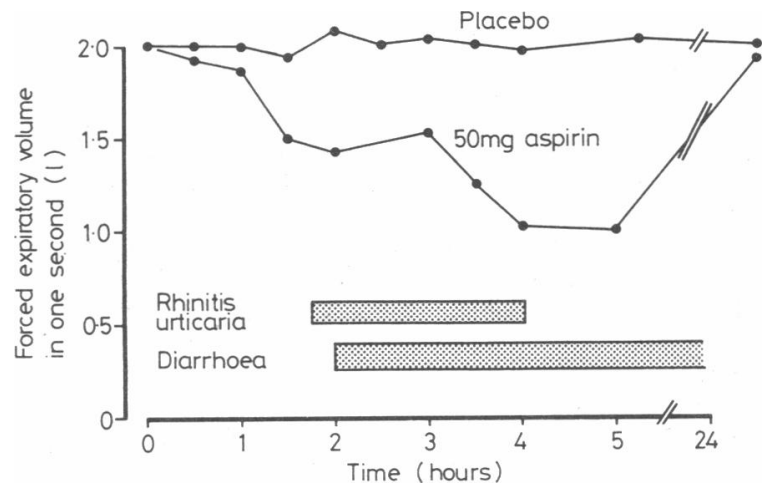

Result of double blind oral provocation with aspirin. Rhinitis, urticaria, and diarrhoea followed administration of aspirin but not administration of lactose placebo on a different day.

of the start of a diet low in natural salicylates and free of artificial dyes and preservatives his symptoms had greatly improved. He subsequently had one normal motion a day without blood or mucus. His urticaria remitted, although he still had exercise induced asthma. Sigmoidoscopic appearances of the rectal mucosa returned to normal.

Apart from occasional days when he departed from his diet and three days when he was treated for a respiratory tract infection with medicines containing azo dyes, this remission was maintained over follow up of 10 and a half months.

\section{Comment}

To our knowledge this is the first reported case of confirmed proctocolitis due to salicylate sensitivity; the condition was associated with asthma, urticaria, and recurrent nasal polyps. Sulphasalazine provoked urticaria after 12 hours. In contrast, aspirin provoked symptoms within one and a half hours. The common side effects of sulphasalazine, and hypersensitivity reactions, have been attributed to absorption of the sulphapyridine moiety released by the action of colonic bacteria. ${ }^{2}{ }^{3}$ Our patient did not react to provocation with sulphapyridine. Three previous patients with bloody diarrhoea exacerbated by sulphasalazine were not subjected to separate salicylate and sulphapyridine provocation tests. ${ }^{4}$

Abdominal symptoms are common in patients with IgE mediated food hypersensitivity. ${ }^{5}$ The mechanism of sensitivity to aspirin, which is common in asthma, ${ }^{1}$ is not clear. It may be an idiosyncratic pharmacological response. Our patient's symptoms when he was not taking medicines containing salicylate were probably due to the azo dyes and benzoate preservatives commonly incorporated in foods and medicines, to which many aspirin sensitive patients react. ${ }^{1}$ His rapid remission with a diet excluding these substances suggests that this sensitivity should be considered in patients with proctocolitis, particularly when this is associated with other atopic manifestations or there is no response to sulphasalazine.

${ }^{1}$ Stenius BS, Lemola M. Hypersensitivity to acetylsalicylic acid (ASA) and tartrazine in patients with asthma. Clin Allergy 1976;6:119-29.

${ }^{2}$ Khan AKA, Howes DT, Piris J, Truelove SC. Optimum dose of sulphasalazine for maintenance treatment in ulcerative colitis. Gut 1980;21: $232-40$

${ }^{3}$ Thomas P, Seaton A, Edwards J. Respiratory disease due to sulphasalazine. Clin Allergy 1974;4:41-7.

4 Schwartz AG, Tarzan SR, Saxon A, Weinstein WM. Sulphasalazineinduced exacerbation of ulcerative colitis. $N$ Englf Med $1982 ; 306: 409-12$.

${ }^{5}$ Lessof MH, Wraith DG, Merrett TG, Merrett J, Buisseret PD. Food allergy and intolerance in 100 patients-local and systemic effects. Qf Med 1980;195:259-71.

(Accepted 7 September 1983)

Department of Medicine, University Hospital of South Manchester, Manchester M20 8LR

D J PEARSON, PHD, MRCP, senior lecturer

N A STONES, $M B$, CHB, senior house officer

$S$ J BENTLEY, MRCP, senior registrar

Department of Pathology, University of Manchester HELEN REID, MRCPATH, lecturer

Correspondence to: Dr D J Pearson.

\section{Moulded baby syndrome and unilateral "tight" hips}

The moulded baby syndrome associates head moulding (plagiocephaly) with pelvic obliquity, scoliosis, torticollis, and bat ears. ${ }^{1}$ The pelvic obliquity results in a unilateral loss of hip abduction in flexion, which may be confused with congenital dislocation or dysplasia of the hip.

\section{Present report}

Between 1967 and 1982, 102 children were referred to Queen Mary's Hospital for Children, Carshalton, with a unilateral reduction of hip abduction in flexion and were found also to have plagiocephaly. Although this had not been noted either by the parents or by the referring doctor, it was usually obvious when sought with the flattened side of the forehead on the same side as the affected hip (figure). Two children had a simple torticollis which responded to stretching, and five had an infantile scoliosis which resolved spontaneously by the age of 2 years.

All the hips were radiographed and were normal after allowing for the pelvic obliquity, which may produce apparent uncovering of the femoral head. Treatment consisted of reassurance and gentle stretching of the hips into abduction in flexion by the parents under the guidance of the physiotherapist. We were able to review 67 patients personally, and all of them had normal hip movements by the age of 18 months.

\section{Comment}

Plagiocephaly combined with a unilateral reduction of hip abduction in flexion predicts a favourable prognosis for the development of the hip, perhaps aided by gentle stretching. As one other child with these physical signs did have radiographic evidence of hip dysplasia and 
eventually required surgery, however, referral to an orthopaedic surgeon of all babies with unilateral loss of hip abduction in flexion is essential.

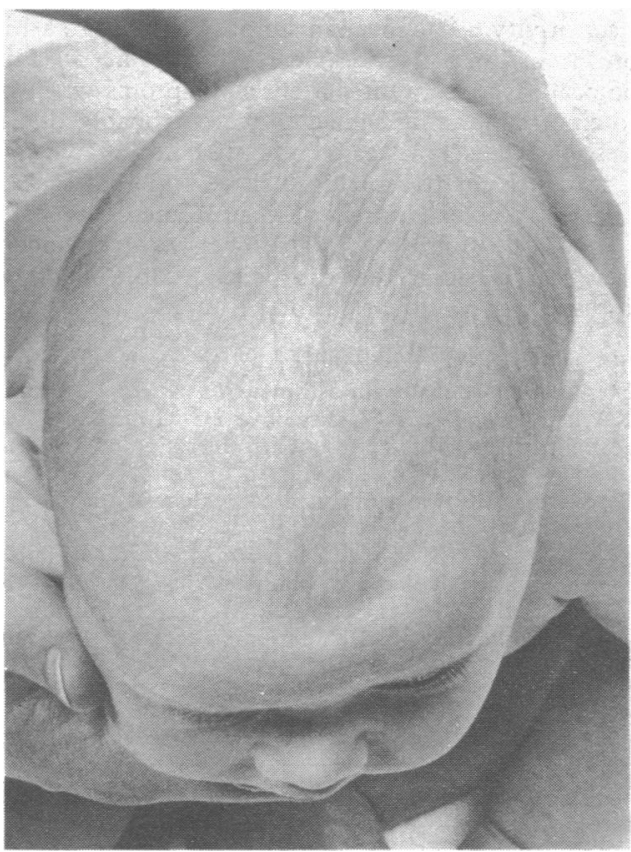

Appearances of plagiocephaly.

We thank the photographic department at Queen Mary's Hospital for Children for the illustration and Miss $S$ Wadd and Mrs R Lenham for secretarial help.

1 Dunn PM. Congenital postural deformities. Br Med Bull 1976;32:71-6.

(Accepted 9 September 1983)

Queen Mary's Hospital for Children, Carshalton, Surrey, and South

West Thames Regional Orthopaedic Training Scheme

CHRISTOPHER GOOD, FRCS, senior orthopaedic registrar

GEOFFREY WALKER, FRCS, consultant orthopaedic surgeon

Correspondence to: Mr Christopher Good, Senior Orthopaedic Registrar, St George's Hospital, London SW17.

\section{Reversible cholestatic jaundice and hyperamylasaemia associated with captopril treatment}

Captopril is a useful drug in the management of intractable heart failure and hypertension unresponsive to conventional treatment. Its adverse effects include agranulocytosis in $0.3 \%$, proteinuria in $1.2 \%$, and pruritus or dermatitis in $7 \%$ of patients. ${ }^{1}$ Although mild increases in liver enzyme activities have been noted in a few patients, ${ }^{2}$ hepatitis is not a recognised complication of treatment with captopril and has been reported in only one patient. ${ }^{3}$

\section{Case report}

A 74 year old woman was admitted to hospital on 12 December 1982 for severe left and right sided heart failure. She had a five year history of ischaemic heart disease, including two episodes of myocardial infarction, and a pacemaker had been implanted for complete atrioventricular block. Her response to treatment, including high doses of frusemide, aminophylline, spironolactone, digoxin, and isosorbide, was not satisfactory. On 2 January 1983 captopril $25 \mathrm{mg}$ by mouth thrice daily was started and was increased subsequently to $50 \mathrm{mg}$ thrice daily, resulting in the disappearance of peripheral oedema and weight loss of $11 \mathrm{~kg}$ within three weeks.
On 28 January she was readmitted because of repeated episodes of absence manifesting as unresponsiveness to external stimuli without loss of consciousness and lasting for several minutes. On admission she was alert without dyspnoea or other signs of heart failure. The pulse was regular and blood pressure was $110 / 70 \mathrm{~mm} \mathrm{Hg}$. A neurological examination and electroencephalogram were normal. Urine analysis and a complete blood count yielded normal results. Her blood urea nitrogen concentration was $19 \mathrm{mmol} / \mathrm{l}$ $(53 \mathrm{mg} / 100 \mathrm{ml})$ compared with $15 \mathrm{mmol} / \mathrm{l}(42 \mathrm{mg} / 100 \mathrm{ml})$ four weeks earlier. Serum aspartate transaminase activity was $208 \mathrm{IU} / 1$ (normal 10$45 \mathrm{IU} / \mathrm{l})$ compared with $26 \mathrm{IU} / \mathrm{l}$ on her previous admission; alkaline phosphatase activity was $350 \mathrm{IU} / 1$ (normal 30-95 IU/1) compared with $135 \mathrm{IU} / 1$, and total serum bilirubin concentration was $46 \mu \mathrm{mol} / 1(2.5 \mathrm{mg} / 100 \mathrm{ml})$. Erythrocyte sedimentation rate increased from 29 to $83 \mathrm{~mm}$ in the first hour.

During the following days her jaundice increased and generalised itching developed. There was no nausea, vomiting, or abdominal pain. The live and spleen were not enlarged. Total bilirubin concentration increased to a maximum of $123 \mu \mathrm{mol} / 1(7 \cdot 2 \mathrm{mg} / 100 \mathrm{ml}$ ) (direct $99 \mu \mathrm{mol} / 1(5 \cdot 8 \mathrm{mg} / 100 \mathrm{ml})$ ) and alkaline phosphatase activity to $1260 \mathrm{IU} / \mathrm{l}$ without a concomitant increase in serum aspartate transaminase or serum alanine transaminase activity. Serum amylase activity was $2000 \mathrm{IU} / \mathrm{ml}$ (normal 70-300) and urine amylase activity $30000 \mathrm{IU} / \mathrm{ml}$ (normal 170-2000). She remained afebrile, and all blood cultures were negative. A technetium scan showed a normal liver and spleen.

After exclusion of extrahepatic biliary obstruction the possibility of drug induced cholestatic jaundice was considered, particularly because a few days earlier, when captopril had inadvertently been stopped for 24 hours, serum amylase activities had dropped from 2000 to $800 \mathrm{IU}$, increasing to 1790 and subsequently to 2400 IU with the resumption of captopril treatment. Treatment with captopril was stopped; the jaundice resolved within one week, and alkaline phosphatase and amylase activities returned to normal within two weeks. No other drugs had been added before the developmen of jaundice or withdrawn before its resolution. Throughout the ensuing three months she continued to enjoy good health and required only minima diuretic treatment. At no time did she complain of abdominal pain or show any other signs of acute pancreatitis.

\section{Comment}

We did not carry out rechallenge followed by a diagnostic liver biopsy in view of our patient's age and her rapid improvement after treatment with captopril was stopped. The course of events was, however, suggestive of a causal relation between captopril and hepatitis. Extrahepatic obstruction was excluded, and the absence of fever or nausea, the negative serological findings, and the predominant cholestatic pattern of liver function tests were more in keeping with drug induced than viral hepatitis. Finally, the transient improvement in serum amylase activity after captopril was inadvertently stopped temporarily and the sustained improvement after it was finally stopped strongly support our contention that captopril was responsible for the observed abnormalities.

The importance of the raised serum and urinary amylase activities in our patient is not certain, particularly in view of the lack of any clinical manifestations and the normal endoscopic retrograde cholangiopancreatogram. Although painless pancreatitis cannot be ruled out, it seems unlikely in the circumstances.

Drugs that produce rashes often cause hepatic damage with both cholestatic and hepatocellular elements. ${ }^{4}$ Thus captopril might be associated with both of these complications. Our report thus emphasises the need for increased attention to hepatic function in patients receiving treatment with captopril.

${ }^{1}$ Vidt DG, Bravo EL, Fouad FM. Drug therapy: captopril. $N$ Engl $\mathcal{H} \mathrm{Med}$ $1982 ; 306: 214-8$.

2 Elmenhary MM, Shaker A, Ramadan M, Hamza S, Tardos SS. Control of essential hypertension by captopril, an angiotensin converting enzyme inhibitor. Br f Clin Pharmacol 1981;11:469-75.

${ }^{3}$ Vandenburg M, Parfrey P, Wright P, Lazda E. Hepatitis associated with captopril treatment. Br $\mathcal{F}$ Clin Pharmacol 1982;11:105-6.

4 Davis M, Williams R. Hepatic disorders. In: David DM, ed. Textbook of adverse drug reactions. Oxford: Oxford University Press, 1977: 146-72.

(Accepted 9 September 1983)

Department of Medicine, Shaare Zedek Medical Centre, Jerusalem Israel

ARI ZIMRAN, MD, resident in medicine

ABRAHAM S ABRAHAM, MD, FRCP, associate professor CHAIM HERSHKO, MD, professor of medicine

Correspondence to: Dr Chaim Hershko. 